\title{
Hepatitis C Virus Infection and Genotypes in Chronic Hemodialysis Patients in Kinshasa: Prevalence and Risk Factors
}

Mathieu Muna Ngilibuma

University of Kinshasa: Universite de Kinshasa

Vieux Momeme Mokoli

University of Kinshasa: Universite de Kinshasa

Yannick Mayamba Nlandu ( $\square$ yannicknlandu@yahoo.fr)

University of Kinshasa: Universite de Kinshasa https://orcid.org/0000-0001-6158-0799

Yannick Mompango Engole

University of Kinshasa: Universite de Kinshasa

Cedric Kabemba llunga

University of Kinshasa: Universite de Kinshasa

Augustin Luzayadio Longo

University of Kinshasa: Universite de Kinshasa

Jeanine Losa Luse

Université de Kinshasa: Universite de Kinshasa

Justine Busanga Bukabau

University of Kinshasa: Universite de Kinshasa

Charles NLombi Mbendi

University of Kinshasa: Universite de Kinshasa

Antoine Wola TShimpi

University of Kinshasa: Universite de Kinshasa

Ernsest Kiswaya Sumaili

University of Kinshasa: Universite de Kinshasa

Nazaire Mangani Nseka

University of Kinshasa: Universite de Kinshasa

Michel Jadoul

Cliniques Universitaires Saint-Luc

Hyppolite Nanituma Situakibanza

University of Kinshasa: Universite de Kinshasa

Jean-Robert Rissassi Makulo

University of Kinshasa: Universite de Kinshasa 
Research article

Keywords: hepatitis C virus, genotype, Hemodialysis, Prevalence, Risk factors, sub-Saharan African

Posted Date: February 8th, 2021

DOl: https://doi.org/10.21203/rs.3.rs-191077/v1

License: (c) (i) This work is licensed under a Creative Commons Attribution 4.0 International License. Read Full License 


\section{Abstract}

\section{Introduction}

The steady increase in the number of chronic hemodialysis patients in sub-Saharan Africa (SSA) calls for improved management of those patients. The present study aimed to determine the frequency of hepatitis $\mathrm{C}$ virus (HCV) infection, the prevalent genotypes and the risk factors associated with HCV in hemodialysis patients in Kinshasa (DR Congo).

\section{Methods}

A cross sectional study was conducted from February to June 2018 in all hemodialysis centers in Kinshasa. Blood samples were collected from 127 chronic hemodialysis patients and tested for the presence of antibodies against HCV. The HCV genotype was identified by real time polymerase chain reaction (RT- PCR).

\section{Results}

Twenty-two (17.3\%) patients were anti-HCV positive, ranging from $0 \%$ to $52.9 \%$ in different centers. Genotype 4 was detected in 18/22 (81.8\%), followed by genotype 2 in 2/22 (9.1\%), and both genotypes 2 and 4 in one patient (4.5\%). One patient had an undetermined genotype (4.5\%). Having received at least 4 transfusions [7,21 (1,09-10,61); $p=0.040)]$, not being under EPO treatment [5,81(1,47-12,96); $p=0.012)]$, being on hemodialysis for at least 14 months $[3,63(1,60-5,05) ; p=0.035)]$ and being dialyzed in an overloaded center $[2,06(0,83-5,86) ; p=0.073)]$ were associated with a greater risk of HCV infection.

\section{Conclusion}

This study highlights the importance of strategies to prevent HCV infection in hemodialysis patients in Kinshasa. This issue is important for SSA countries which are facing several economic and logistical challenges.

\section{Introduction}

The infection risk in hemodialysis (HD) patients is considerable, explained by multiple factors including impaired immunity, comorbidities such as diabetes, and the need for frequent hospitalizations and surgical interventions. HD itself further involves frequent and prolonged exposure to blood by means of vascular access, and the proximity of other patients during dialysis sessions. Thus hepatitis $\mathrm{C}$ virus $(\mathrm{HCV})$ infection is rather common in HD patients. Identifying acute HCV infections is often difficult, as most patients tend to be asymptomatic. However, $75-85 \%$ of subjects with HCV infection will develop chronic hepatitis, and $10-20 \%$ will develop liver cirrhosis over 20 years $(1,2)$. Therefore, it is important that dialysis centers have adequate processes for preventing HCV infection, including training of staff and regular audits. 
The Dialysis Outcomes and Practice Patterns Study (DOPPS) reported recently an overall HCV prevalence of $9.9 \%$ among adult hemodialysis patients in high- and middle-income countries (3). Actually, the prevalence varied greatly from one country to another (ranging from $4.1 \%$ in Belgium to $20.1 \%$ across the Gulf Cooperation Council Countries), and from one dialysis center to another (3). Compared to HCVnegative patients, HCV-positive patients enrolled in DOPPS had a higher risk of all-cause and liver-related mortality and all-cause hospitalization (4). Thus the KDIGO 2018 guideline recommends that each hemodialysis center carefully follows every HCV-infected dialysis patient, measures viral load, assesses the extent of hepatic fibrosis, and establishes optimal treatment strategies (5). Furthermore with the recent Direct-acting Antiviral Agent (DAA), elimination of HCV from the general population and from dialysis centers may be possible, thereby reducing the considerable morbidity and mortality associated with this disease; but for economic reasons, DAAs are rarely administered in sub-Saharan Africa (SSA) (6). In the absence of a vaccine, routine screening and adherence to standard infection control practices will remain the key strategies for preventing HCV transmission in hemodialysis centers (5).

Data on HCV infection in hemodialysis patients in SSA are scarce. There have been a few single-center studies and none assessed risk factors for hepatitis $C$ virus infection (7-9).

Recent HD studies from SSA generally report higher prevalence of HCV compared to western countries. The present multicentric study aimed to determine the prevalence of HCV infection and genotypes in all Kinshasa (Democratic Republic of Congo) hemodialysis centers and identify the risk factors associated with HCV infection.

\section{Methods}

The study was performed in all hemodialysis centers of Kinshasa, the capital city of DRC. A total of 185 patients from 6 hemodialysis centers were considered to participate in this cross sectional study between February and June 2018. Only 127 patients meeting inclusion criteria and giving informed consent were investigated. The remaining 58 patients could not been tested for the following reasons: acute kidney injury (AKI) (6), chronic hemodialysis treatment for less than 3 months (18), refusal to take samples (2), travel (6) or lost to follow-up during the investigation (26).

The parameters of interest related to patients were: age, sex, marital status, blood group, medical history (viral status at the initiation of hemodialysis including Hepatitis B Virus = HBV, Human Immunodeficiency Virus = HIV and HCV), number of transfusions since HD start, nosocomial exposure (Dental care, Piercing or Tattooing, Surgical intervention or endoscopic treatment) IV Drug addiction, and known liver disease.

Concerning parameters related to hemodialysis, we recorded time on hemodialysis in months, cause of chronic kidney disease (CKD) and the type of vascular access (AVF, KT, Prosthesis).

Blood $(10 \mathrm{ml})$ was obtained from each patient before the hemodialysis session, and centrifuged immediately. Serum was stored in aliquots at $-80^{\circ} \mathrm{C}$. All samples were subsequently subjected to liver function tests: alanine aminotransferase $(\mathrm{U} / \mathrm{I})$, aspartate aminotransferase $(\mathrm{U} / \mathrm{I})$, gamma glutamyl 
transpeptidase $(\mathrm{U} / \mathrm{l})$, and bilirubin concentration $(\mathrm{mg} / \mathrm{dl})$ in the laboratory of LOMO MEDICAL, Kinshasa. Anti-HCV antibodies were detected by a third generation ELISA (Huma Reader Single ${ }^{\circledR}$, France). The third generation assay of ELISA detects antibodies to three HCV antigens (c22-3, c200, and NS5). In collaboration with the Indian laboratory of HJ Hospital in Kinshasa, HCV-RNA testing was performed using reverse transcription polymerase chain reaction (RT-PCR) (Cobas $4800 \AA$, Roche, France) with a detection limit of 100 copies $/ \mathrm{ml}$.

The parameters of interest related to hemodialysis centers were: number of treatment rooms in the center, number of machines in the center, number of staff (doctors, nurses and other caregivers), and number of patients on HD. All centers used high permeability dialyzers and respected the recommended duration of disinfection between two dialysis sessions.

The operational definitions used were as follows:

- HCV infection: presence of anti-HCV antibodies by the 3rd generation ELISA and confirmation of the HCV viral infection by RT-PCR;

- Chronic hemodialysis: any patient with CKD stage 5 on hemodialysis for more than 3 months;

- HCV seroconversion: any patient included in the study with a previous negative HCV antibody but who during the study had a positive serology for HCV by the 3rd generation ELISA method.

Depending on the prices of HD sessions, the HD centers were grouped into category A (which apply low prices $=1 / 3$ ) and category B (which apply standard prices $=200 \$$ US)

\section{Statistical analyses}

Statistical analyses were performed using SPSS 21.0 for Windows (SPSS Inc., Chicago, IL, USA). Comparisons between groups were performed using Student's t test, Fisher's exact test and the Chi square test, as appropriate. Logistic regression analysis was used to identify the risk factors associated with HCV infection. A p-value $<0.05$ was considered as statistically significant.

\section{Ethical considerations}

The study protocol was approved by the ethics committee of the Public Health School of the University of Kinshasa (ESP/CE/032/2018). The rules of anonymity were respected both for the names of the patients and the medical structures (hemodialysis centers). All patients screened positive for $\mathrm{HCV}$ infection were referred to gastroenterologists for evaluation and treatment.

\section{Results}

Of the 127 patients tested for HCV antibodies, 22 were positive (17.3\%). All positive samples were confirmed by RT-PCR. We had 2 cases of seroconversion (1.9\%) compared to previous tests performed three to six months earlier. Viral load varied between 1,567 and 3,310,000 copies/ml (median: 14,400 copies / ml). Figure 1 shows that genotype 4 was the most common.Table 1 shows that the frequency of 
infection varied between centers, ranging from 0 to $52.9 \%$. The HCV infected patients had a time on hemodialysis treatment, were less frequently under EPO and had received more blood transfusions since the start of hemodialysis (Table 2). Multivariable analysis (Table 3) showed that having received 4 Transfusions multiplied the risk of being infected by $7.21(1.09-10.61)$. The risk was multiplied by 9.59 (1.67-14.94) beyond 8 transfusions. Not receiving EPO treatment increased the risk by 5.81 (1.4712.96). After 14 months undergoing hemodialysis treatment, the risk of being infected by HCV was multiplied by $3.63(1.60-5.05)$. Compared to the 5 other centers, the patients followed in center 1 had a risk multiplied by $2.06(0.83-5.86)$.

Table 1

Frequency of HCV infection by hemodialysis center

\begin{tabular}{|cccccc|}
\hline $\begin{array}{l}\text { Hemodialysis } \\
\text { center }\end{array}$ & $\begin{array}{l}\text { Number of } \\
\text { rooms }\end{array}$ & $\begin{array}{l}\text { Number of } \\
\text { Nurses/doctors }\end{array}$ & $\begin{array}{l}\text { Total number of } \\
\text { patients }\end{array}$ & $\begin{array}{l}\text { Patients } \\
\text { included }\end{array}$ & HCV+ \\
\hline 1 A & 2 & 12 & 51 & 17 & 9 \\
\hline 2 B & 2 & 8 & 17 & 16 & 5 \\
\hline 3 B & 4 & 14 & 54 & 43 & 5 \\
\hline 4 B & 17 & 30 & 24 & 2 \\
\hline 5 B & 2 & 10 & 27 & 22 & $(11.6)$ \\
\hline 6 B & 2 & 10 & 5 & 5 & 0 \\
\hline $\begin{array}{l}\text { A: center applying } 1 / 3 \text { of standard dialysis session prices B: center applying standard dialysis session } \\
\text { prices. }\end{array}$ & 2 & & & \\
\hline
\end{tabular}


Table 2

Patient characteristics according to HCV infection status

\begin{tabular}{|c|c|c|c|}
\hline \multirow[t]{2}{*}{ Variables } & HCV+ & HCV- & \multirow[t]{2}{*}{$\mathbf{p}$} \\
\hline & $\mathrm{n}=\mathbf{2 2}$ & $n=105$ & \\
\hline Age & $57.3 \pm 15.2$ & $54.3 \pm 13.7$ & 0.36 \\
\hline \multicolumn{4}{|l|}{ Sexe } \\
\hline Men & $15(68.2)$ & $67(63.8)$ & 0.70 \\
\hline Women & $7(31.8)$ & $38(36.2)$ & \\
\hline Time on hemodialysis & $27.4 \pm 8.7$ & $21.3 \pm 6.2$ & $<0.001$ \\
\hline \multicolumn{4}{|l|}{ Cause of CKD } \\
\hline Diabetic nephropathy & $7(31.8)$ & $40(38.1)$ & 0.63 \\
\hline Nephrosclerosis & $9(40.9)$ & $38(36.2)$ & \\
\hline Glomerulonephritis & $6(27.3)$ & 19(18.1) & \\
\hline \multicolumn{4}{|l|}{ Vascular access } \\
\hline Fistula & $1(4.6)$ & $23(21.9)$ & 0.06 \\
\hline Catheter & $21(95.5)$ & $82(78.1)$ & \\
\hline Number of transfusions & $4.6 \pm 1.0$ & $3.6 \pm 2.2$ & 0.04 \\
\hline HBV serology positive & $0(0.0)$ & $3(2.9)$ & 0.42 \\
\hline HIV serology positive & $1(4.5)$ & $3(2.9)$ & 0.70 \\
\hline EPO & $7(31.8)$ & $76(72.4)$ & $<0.001$ \\
\hline
\end{tabular}


Table 3

Risk factors of HCV infection in chronic hemodialysis patients

\begin{tabular}{|c|c|c|c|c|}
\hline \multirow[t]{2}{*}{ Factors } & \multicolumn{2}{|c|}{ Univariate analysis } & \multicolumn{2}{|c|}{ Multivariate analysis } \\
\hline & $\mathbf{p}$ & OR (Cl 95\%) & $p$ & aOR (Cl 95\%) \\
\hline Catheter vs fistula & 0.039 & $5.89(1.72-46.16)$ & 0.363 & $2.83(0.30-6.49)$ \\
\hline \multicolumn{5}{|l|}{ Number of transfusions } \\
\hline$<4$ & reference & & & 1 \\
\hline $4-8$ vs $<4$ & 0.037 & $5.04(1.11-22.96)$ & 0.040 & $7.21(1.09-10.61)$ \\
\hline$>8$ vs $<4$ & 0.001 & $11.20(2.56-49.05)$ & 0.011 & $9.59(1.67-14.94)$ \\
\hline No EPO vs EPO & 0.001 & $5.62(2.08-15.17)$ & 0.012 & $5.81(1.47-12.96)$ \\
\hline \multicolumn{5}{|l|}{ Duration on HD } \\
\hline$\geq 14$ vs $<14$ months & 0.008 & $4.28(1.50-6.22)$ & 0.035 & $3.63(1.60-5.05)$ \\
\hline Center A vs centers $B$ & $<0.001$ & 8.39 (2.75-25.59) & 0.073 & $2.06(0.83-5.86)$ \\
\hline EPO : erythropoietin & & & & \\
\hline
\end{tabular}

\section{Discussion}

This study shows a high frequency of HCV infection in patients on chronic hemodialysis in Kinshasa, with disparities between centers. Genotype 4 was the most common. The risk factors associated with $\mathrm{HCV}$ infection were the number of blood transfusions, the absence of EPO treatment, the time on HD as well as the characteristics of the centers.

Studies in Europe indicate a decrease in incidence of HCV infection in parallel with prevalence in hemodialysis centers (3) over the last 10 years, while others countries, especially in Eastern Europe, maintain a high incidence (10). The frequency of HCV infection we observed is higher than found in hemodialysis centers in Western Europe and North America $(3,4,10)$. Reducing the number of blood transfusions in people on dialysis through administration of erythropoietin, aseptic measures including the use of single use disposables such as syringes and use of the right disinfectants, are other factors that have contributed to lowering the frequency of HCV infection in developed countries (5), as did the testing of blood donors for HCV from 1992 with increasingly sensitive tests (11). The recent treatments of $\mathrm{HCV}$, particularly with DAA, may well increase the gap between countries because availability of DAA is not guaranteed in several countries including those in SSA (12). However, the average prevalence in this study are similar to those reported in other dialysis centers in SSA (7-9). 
It is also known that in each country, the frequency of HCV infection in hemodialysis varies from center to center (3). This finding was confirmed in our study where we observed a disparity between the centers, with the frequency of HCV infection varying between 0 and $52.9 \%$.

Despite the fact that the number of participants was low (only 17 patients out of 51) in the center practicing lower prices per HD session and the serological status at the initiation of HD was not well established, the high frequency of HCV infection in this center could be explained by the high treatment rates with an inadequate nursing medical staff-patients ratio probably responsible for nosocomial transmission. Because in a country like the DRC where dialysis is not subsidized and where social security and mutual funds are poorly developed, the consumables used in dialysis inevitably participate in the calculation of the prices of hemodialysis sessions (13). The motivation of nursing/medical staff and their number in relation to patients treated also have an impact on the quality of care. But these aspects were not analyzed in our study.

Only 2 patients seroconverted to HCV. This is nevertheless important knowing that, in accordance with the recommendations of the Congolese Society of Nephrology (SOCONEPH), the previous control went back to 6 months previously, unless the patient had to move to another dialysis center. In this case, serology checks for HCV, HIV and HBV are carried out systematically. The rate of seroconversion found (1.9\%) is almost identical to that reported in the literature (14-16). The general measures that are recommended to prevent seroconversion are: limitation of handling and safe disposal of sharp or stinging objects and contaminated waste, hand washing, use of single-use surgical gloves, changed after each patient, training of personnel, the use of machines which allow thermal and chemical disinfection, disinfection of the external surfaces of the machine and HD environment (5).

Knowledge of the HCV genotype is important for the choice of antiviral treatment. As in studies conducted in the general population in SSA (17), and even in hemodialysis patients treated in Angola (18), genotype 4 was predominant in our study.

Several factors explain the HCV infection in hemodialysis, but the most frequently reported in the literature are blood transfusions and the duration of treatment in hemodialysis. Other factors were highlighted by the multicenter study (DOPPS) such as male gender, diabetes mellitus, black race, hepatitis $B$ and alcohol (3). In our study, HCV infection was associated with the number of blood transfusions, the duration of hemodialysis, not taking EPO, and the type of hemodialysis center. Strengthening the national health system, improving the country's economic situation, can help increase the use of EPO in hemodialysis; which will reduce the number of transfusions. If a blood transfusion is necessary, a more demanding qualification of the blood must be ensured in the blood banks. The risk associated with the type of hemodialysis center shows that while improving access to treatment thanks to lower prices, the prevention and hygiene measures described above must be observed. Indeed a link with suboptimal hygienic precautions seems likely. Taking into account the very high frequency of HCV infection in this type of center, i.e. roughly one in 2 patients, we can wonder whether it is not advisable to dialyze these patients in isolated rooms from other uninfected patients? Admittedly this would equal to accept 
suboptimal hygienic precautions, and should be a last option resort. The hemodialysis setting has unique features that facilitate transmission of HCV, such as high risk of blood contamination of surfaces, objects and devices, and a large number of patients treated simultaneously in a shared space. In SSA countries, risk factors associated with HCV infection may be due to unsafe medical practices or other factors such as familial transmission, mother's HCV status, or illiteracy. HCV prevention and control programs should include health education, increased community awareness towards the disease, controlling infection distribution in health-care centers, proper sterilization of medical and dental instruments, and ensuring safe supply of blood and blood-products (19).

\section{Conclusion}

The findings of this study highlight the importance of preventive strategies to prevent the transmission of HCV infection to hemodialysis patients. This issue is important for SSA countries which are facing several economic and logistical challenges.

\section{Abbreviations}

AKI: Acute kidney Injury; CKD: Chronic kidney Disease; DAA: Direct-acting Antiviral Agent; DOPPS: Dialysis Outcomes and Practice Patterns Study; DR Congo: Democratic republic of Congo; EPO: erythropoietin; HD: hemodialysis; HBV: Hepatitis B Virus ; HCV: Hepatitis C virus; HIV: Human Immunodeficiency Virus ; RT-PCR: real time polymerase chain reaction; SSA: sub-Saharan Africa.

\section{Declarations}

\section{Ethical approval and consent to participate}

The study protocol was approved by the ethics committee of the Public Health School of the University of Kinshasa (ESP/CE/032/2018). The rules of anonymity were respected both for the names of the patients and the medical structures (hemodialysis centers). All patients giving informed consent. The patients screened positive for HCV infection were referred to gastroenterologists for evaluation and treatment.

\section{Consent for publication}

Not applicable

\section{Availability of data and materiels}

The dataset supporting the conclusion of this article are available

\section{Competing interests}


The authors declare that the research was conducted in the absence of any commercial or financial relationships that could be considered as a potential conflict of interest.

\section{Funding}

None

\section{Author contributions}

MJR and MMN conceived the idea, designed and supervised the study, had full access to all data and took responsibility for the integrity of the data. MMN collected the clinical and laboratory data. MJR analysed data and performed statistical analysis. All co-authors reviewed and approved the final version.

\section{Acknowledgments}

The authors gratefully thank the staff of the hemodialysis centers in Kinshasa, for their commitment to always provide the utmost care to our patients.

\section{References}

1. Liang TJ, Rehermann B, Seeff LB, Hoofnagle JH. Pathogenesis, natural history, treatment, and prevention of hepatitis C. Ann Intern Med. 2000;132:296-305.

2. Thomas DL, Seeff LB. Natural history of hepatitis C. Clin Liver Dis. 2005;9:383-98.

3. Jadoul M, Bieber BA, Martin P, Akiba T, Nwankwo C, Arduino JM. Prevalence, incidence, and risk factors for hepatitis $C$ virus infection in hemodialysis patients. Kidney Int. 2019;95:939.

4. Goodkin DA, Bieber B, Jadoul M, Martin P, Kanda E, Pisoni RL. Mortality, hospitalization, and quality of life among patients with hepatitis $C$ infection on hemodialysis. Clin J Am Soc Nephrol. 2017;12(2):287-97.

5. Jadoul M, Berenguer MC, Doss W, Fabrizi F, Izopet J, Jha V, et al. Executive summary of the 2018 KDIGO Hepatitis C in CKD Guideline: welcoming advances in evaluation and management. Kidney Int. 2018;94:663-73.

6. Heidi Barth. Hepatitis $C$ virus: Is it time to say goodbye yet? Perspectives and challenges for the next decade. World J Hepatol. 2015;7(5):725-37.

7. ASS Baby M, Fongoro S, Konate MK, Diarra A, Kouriba B, Maiga MK, et al. Prévalence et facteurs associés au portage du virus de l'hépatite $\mathrm{C}$ chez les hémodialysés chroniques au $\mathrm{CHU}$ du point $\mathrm{G}$, Bamako Mali. Mali Med. 2011;26:2.

8. Mokoli VM, Bukabau JB, Izeidi IP, Luse JL, Engole Y, Makulo JRR, et al. La diurèse résiduelle à l'initiation de l' Hémodialyse et profil clinico biologique des patients insuffisants rénaux en milieu 
hospitalier de Kinshasa, RDC. Ann Afri Med. 2016;9(4):2377-85.

9. Ummate I, Denue BA, Kida IM, Ohioma OJ, Baba DB, Goni W. Risk factors for hepatitis C virus seropositivity among haemodialysis patients receiving care at Kidney Centre in a tertiary health facility in Maiduguri, Nigeria. Pan Afr Med J. 2014;19:305.

10. Caragea DC, Mihailovici AR, Streba CT, Schenker M, Ungureanu B, Caragea IN. Hepatitis C Infection in Hemodialysis Patients. Curr Health Sci J. 2018;44(2):107-12.

11. Global surveillance and control of hepatitis C. Report of a WHO Consultation organized in collaboration with the Viral Hepatitis Prevention Board, Antwerp, Belgium. J Viral Hepatitis. 1999;6:35-47.

12. Falade-Nwulia $O$, Suarez-Cuervo $C$, Nelson DR. Oral direct-acting agent therapy for hepatitis $C$ virus infection: a systematic review. Ann Intern Med. 2017;166:637-48.

13. Izeidi PPM, Nlandu YM, Lepira FB, Makulo JRR, Engole YM, Mokoli VM, et al. Cost estimate of chronic haemodialysis in Kinshasa, the Democratic Republic of the Congo: A prospective bicentric study. Hemodial Int 2019 Nov 21. doi: 10.1111/hdi.12802.

14. Chan TM, Lok ASF, Cheng IKP, Chan RT. Prevalence of hepatitis $C$ virus infection in hemodialysis patients: a longitudinal study comparing the results of RNA and antibody assays. Hepatology. 1993;17:5-8.

15. Jadoul M, Cornu C, van Ypersele de Strihou C. Universal precautions prevent hepatitis $C$ virus transmission: a 54 month follow-up of the Belgian multicenter study. Kidney Int. 1998;53:1022-5.

16. Jadoul M. Transmission routes of HCV infection in dialysis. Nephrol Dial Transplant. 1996;11(4):368.

17. Riou Julien. La séroprévalence du virus de l'hépatite $C$ en Afrique: une revue systématique avec métaanalyse. Thèse pour le diplôme de docteur en Médecine. France: Université de Paris-Est Creteil; 2016.

18. Borges LFC, Zalis MG, Santoro-Lopes G, Varella RB. Hepatitis C virus genotypes in hemodialysis patients in Angola. J Med Virol. 2019;91(3):518-21.

19. Petruzziello A, Marigliano S, Loquercio G, Cozzolino A, Cacciapuoti C. Global epidemiology of hepatitis $C$ virus infection: An up-date of the distribution and circulation of hepatitis $C$ virus genotypes. World J Gastroenterol. 2016;22(34):7824-40.

\section{Figures}



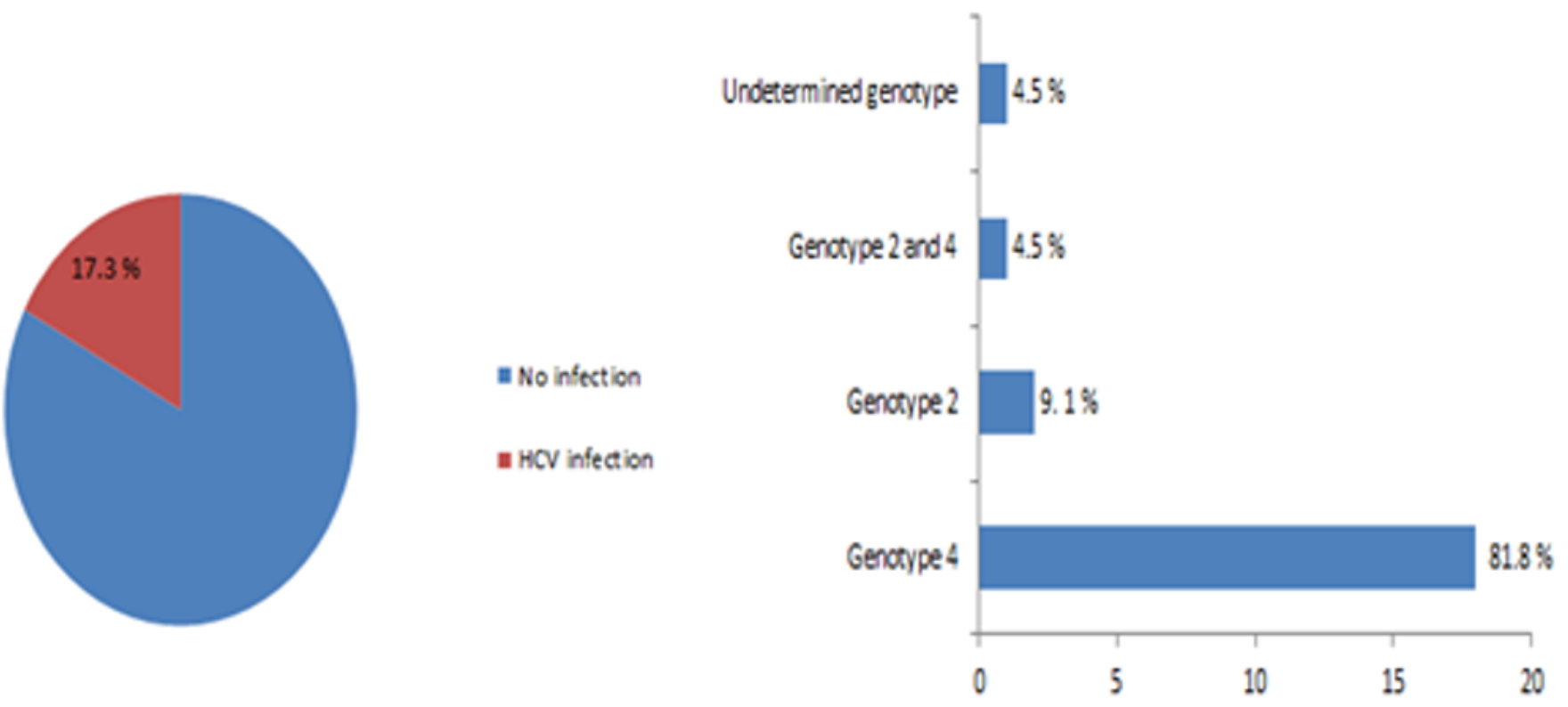

Figure 1

Prevalence of HCV infection (A) and HCV genotypes (B) in chronic HD patients in Kinshasa. 